Article

\title{
Ruthenium Oxide Nanorods as Potentiometric pH Sensor for Organs-On-Chip Purposes
}

\author{
Esther Tanumihardja *, Wouter Olthuis and Albert van den Berg
}

BIOS Lab on a Chip Group, Technical Medical Centre, MESA + Institute for Nanotechnology, and Max Planck Center for Complex Fluid Dynamics, University of Twente, 7522 NB Enschede, The Netherlands; w.olthuis@utwente.nl (W.O.); a.vandenberg@utwente.nl (A.v.d.B.)

* Correspondence: e.tanumihardja@utwente.nl

Received: 10 June 2018; Accepted: 28 August 2018; Published: 1 September 2018

\begin{abstract}
A ruthenium oxide ( $\mathrm{RuOx})$ sensor for potentiometric $\mathrm{pH}$ sensing is currently being developed for organs-on-chip purposes. The sensor was fabricated from a $\mathrm{Ru}(\mathrm{OH})_{3}$ precursor, resulting in RuOx nanorods after heating. An open-circuit potential of the RuOx electrode showed a near-Nernstian response of $-58.05 \mathrm{mV} / \mathrm{pH}$, with good selectivity against potentially interfering ions (lithium, sulfate, chloride, and calcium ions). The preconditioned electrode (stored in liquid) had a long-term drift of $-0.8 \mathrm{mV} / \mathrm{h}$, and its response rate was less than $2 \mathrm{~s}$. Sensitivity to oxygen was observed at an order of magnitude lower than other reported metal-oxide $\mathrm{pH}$ sensors. Together with miniaturizability, the $\mathrm{RuOx} \mathrm{pH}$ sensor proves to be a suitable $\mathrm{pH}$ sensor for organs-on-chip studies.
\end{abstract}

Keywords: ruthenium oxide; potentiometric sensor; $\mathrm{pH}$ sensor; organs-on-chip; lab-on-chip

\section{Introduction}

Organs-on-chips are a new, in vitro model of human tissue, where cells are cultured and perfused in microfluidic devices. The devices can be configured to mimic cells' microenvironments as realistically as possible (in terms of physical/chemical cues, tissue-tissue interfaces, and perfusion). This way, the cells can replicate human physiology and pathology at organ-level, thus providing an improved model to the too-simplistic 2D (or even 3D) cell culture. Applications of organs-on-chip as an alternative to the animal models are thus more ethical, physiologically representative/predictive, and also personalizable [1-3].

Many different kinds of organs-on-chips have been developed over the years [3]. Typically, the cells have been cultured in micrometer-size chambers or channels, leaving low accessibility to probe or monitor the cells from outside the chip. The small dimensions also mean that very minute amounts of medium is involved, making offline sampling also limited. Consequently, microsensors can be of great value in providing readouts for organs-on-chip studies. Miniaturized sensors can be placed close to the cells, enabling accurate non-invasive online monitoring of minute analytes.

This work explores on-chip $\mathrm{pH}$ sensors, which are useful for long-term cell-culture/differentiation and tissue studies. Metal oxide is a well-known class of on-chip $\mathrm{pH}$ sensors for its robust, inert, and miniaturizable properties. Although the metal oxides (where the most commonly investigated ones are $\mathrm{SbO}_{2}, \mathrm{TiO}_{2}, \mathrm{CuO}, \mathrm{IrO}_{2}$, and $\mathrm{RuO}_{2}$ ) show a Nernstian response to proton concentration [4], metal oxide electrodes often suffer from sensitivity to other oxidizing/reducing agents [4,5]. An especially critical and unavoidable oxidizing agent for organs-on-chip studies is dissolved $\mathrm{O}_{2}$, where it often acts as an operational parameter. Studies on $\mathrm{IrO}_{2}$, for instance, have reported a potential response as much as $80 \mathrm{mV}$ going from a deoxygenated to oxygenated buffer [6,7]. Ruthenium oxide (RuOx), however, might be an exception to this shortcoming $[4,8]$, and is therefore the focus of this work. 
$\mathrm{RuOx}$ is proton-sensitive due to the reversible redox equilibrium between two different solid phases/oxidation states of the metal oxides, in which proton is involved [8-10]:

$$
\mathrm{RuO}_{2} \cdot 2 \mathrm{H}_{2} \mathrm{O}+\mathrm{H}^{+}+\mathrm{e}^{-} \leftrightarrow \mathrm{H}_{2} \mathrm{O}+\mathrm{Ru}(\mathrm{OH})_{3}
$$

An adsorbed proton leads to the attraction of an electron through this conducting oxide, resulting in the reduction of the $\mathrm{Ru}$ ion. This leads to a net potential change, generating measurable change in an open-circuit potential.

Recent years have seen many works on the RuOx pH sensor for different applications. Table 1 summarizes the recent works on the $\mathrm{RuOx} \mathrm{pH}$ sensor, as well as their results and applications. While $\mathrm{pH}$ sensitivity, range, drift, and response time have commonly been characterized, very few have touched on oxygen sensitivity. Lonsdale et al. [11] described the elimination of oxygen sensitivity through the addition of a $\mathrm{Ta}_{2} \mathrm{O}_{5}$ layer on $\mathrm{RuO}_{2}$. Xu et al. [12] showed there to be a high resemblance between calibration curves of $\mathrm{RuO}_{2}-\mathrm{MWCNTs}$ measuring in oxygen-saturated and nitrogen-saturated buffers. However, there no studies have been done on characterized oxygen sensitivity of $\mathrm{RuO}_{2}$ in organs-on-chip configuration so far.

Table 1. Summary of recent works on $\mathrm{RuO}_{2} \mathrm{pH}$ sensors, their results, and applications.

\begin{tabular}{|c|c|c|c|c|c|c|}
\hline Material & pH Range & $\begin{array}{c}\text { pH Sensitivity } \\
(\mathrm{mV} / \mathrm{pH})\end{array}$ & $\begin{array}{l}\text { Response } \\
\text { Time (s) }\end{array}$ & $\begin{array}{c}\text { Drift } \\
\text { (mV/Hour) }\end{array}$ & Application & Ref \\
\hline $\mathrm{RuO}_{2}-\mathrm{Ta}_{2} \mathrm{O}_{5}$ & - & -55.3 & $5-136$ & 7.2 & $\begin{array}{c}\mathrm{pH} \text { sensing of } \\
\text { common beverages }\end{array}$ & [11] \\
\hline $\mathrm{RuO}_{2}$ & $1-10$ & -77.74 & $<20$ & 93.3 & $\begin{array}{c}\text { Detection of } \\
\text { Helicobacter pylori }\end{array}$ & [13] \\
\hline $\mathrm{RuO}_{2}$ & $2-11$ & -56 & $60-120$ & - & - & [14] \\
\hline Pt-doped $\mathrm{RuO}_{2}$ & $2-13$ & -58 & $1-2$ & 0.002 & $\begin{array}{l}\text { Water quality } \\
\text { monitoring }\end{array}$ & [15] \\
\hline $\mathrm{RuO}_{2}-\mathrm{MWCNTs}$ & $2-12$ & -55 & $<40$ & - & - & [12] \\
\hline $\mathrm{RuO}_{2}$ nanorods & $2-10$ & -58 & $<2$ & -0.8 & Organs-on-chip & This work \\
\hline
\end{tabular}

In this work, the $\mathrm{RuOx}$ electrode was fabricated from a $\mathrm{Ru}(\mathrm{OH})_{3}$ precursor, which was precipitated from $\mathrm{Ru}^{3+}$ and $\mathrm{OH}^{-}$ions. The precursor was heated to form $\mathrm{RuO}_{2}$ with nanorods morphology. The same electrode was intended to be developed into a dual sensor-a potentiometric $\mathrm{pH}$ sensor and amperometric nitric oxide sensor, where the nanorods morphology is desired for the latter. Therefore, the same $\mathrm{RuOx}$ nanorods were studied as a $\mathrm{pH}$ sensor, although the morphology did not theoretically improve the potentiometric signal.

This contribution evaluates the suitability of $\mathrm{RuO}_{2}$ nanorods as an on-chip $\mathrm{pH}$ sensor in novel organs-on-chip settings. Its drift behavior, selectivity, response time, and oxygen sensitivity are presented and discussed. The first organs-on-chip application for the $\mathrm{RuOx} \mathrm{pH}$ sensor envisions a hypoxia study of cardiomyocytes. In a hypoxic condition, cardiomyocytes undergo anaerobic glycolysis which results in a drop in $\mathrm{pH}$ as much as $1-2 \mathrm{pH}$ units. During the study, oxygen levels were expected to vary from fully oxygenated to deoxygenated. Applicability of the sensor is currently being assessed with this application in mind.

\section{Materials and Methods}

\subsection{Electrode Fabrication}

The RuOx electrode was fabricated according to the protocol of Chen et al. [16] $\mathrm{RuCl}_{3} \cdot n \mathrm{H}_{2} \mathrm{O}$ (Aldrich, Saint Louis, MO, USA, 99.98\%) was dissolved in de-ionized water to make $10 \mathrm{~mL}$ of $5 \mathrm{mM}$ $\mathrm{RuCl}_{3}$ solution. $5 \mathrm{mM} \mathrm{NaOH}$ (Aldrich, 98\%) solution was then added drop by drop to the solution, until the solid $\mathrm{Ru}(\mathrm{OH})_{3}$ precursor precipitated. Precipitation typically occurred around $\mathrm{pH} 4$ (from 
an initial $\mathrm{pH}$ of around 2). The precursor was then isolated by centrifugation and suspended in DI water. The resuspension was spread onto clean substrate (sputtered circular Pt electrode, $2.4 \mathrm{~mm}$ in diameter, on glass chip), left to dry in room temperature, and then heated to $350{ }^{\circ} \mathrm{C}$ in a preheated oven (atmospheric environment) for $3 \mathrm{~h} . \mathrm{RuO}_{2}$ nanorods were formed after the heat treatment, as confirmed by scanning electron microscopy (SEM) imaging.

Pt electrodes on glass chips were first electrochemically cleaned before being used as $\mathrm{RuOx}$ substrate by applying cyclic potential sweeps (20 times with a scan rate of $100 \mathrm{mV} / \mathrm{s}$ in $0.5 \mathrm{M} \mathrm{H}_{2} \mathrm{SO}_{4}$ between -0.6 and $1 \mathrm{~V}$ (vs. $\mathrm{Ag} / \mathrm{AgCl}$ ), ending in $1 \mathrm{~V}$ ).

\subsection{Experimental Setup}

The modified chip with grown RuOx nanorods was used for most experiments, unless stated otherwise. The glass chip was used with a Teflon chip holder, made in-house. The chip holder exposed the electrodes' active areas to the electrolyte chamber. All potentials were measured against a liquid-junction $\mathrm{Ag} / \mathrm{AgCl}$ (satd. $\mathrm{KCl}$ ) reference electrode ( $\mathrm{CH}$ Instruments), typically placed $\sim 5 \mathrm{~mm}$ from the RuOx electrode. The setup was placed inside a Faraday cage during all measurements. All measurements were carried out using a Bio-Logic SP300 bipotentiostat (input impedance of $>100 \mathrm{G} \Omega$ ) and were performed at room temperature of around $22^{\circ} \mathrm{C}$.

\subsection{Measurement Protocol}

Open-circuit potential measurements were performed in buffer solutions. $\mathrm{pH} 4$ used a potassium hydrogen phthalate buffer, $\mathrm{pH} 5$ acetic acid/sodium acetate buffer, $\mathrm{pH} 7$ disodium hydrogen phosphate/potassium hydrogen phosphate buffer, $\mathrm{pH} 8$ phosphate buffered saline, and $\mathrm{pH} 10$ boric acid/sodium hydroxide buffer. The $\mathrm{pH}$ of the solutions was confirmed with a Mettler-Toledo SevenMulti pH meter, calibrated with standard buffer solutions of $\mathrm{pH} 4,7$, and 10.

For the $\mathrm{pH}$ response experiment, the open-circuit potential was recorded for $150 \mathrm{~s}$ at $1 \mathrm{~s}$ intervals. The last point was taken as a potential response to determine $\mathrm{pH}$ sensitivity. Interference experiments were done in air-saturated $\mathrm{pH} 7.4$ phosphate-buffered saline (PBS) buffer. Ions of different concentrations were dissolved in the buffer and measured.

Longer measurements in air-saturated $\mathrm{pH}$ buffer were done for the drift experiment. Drift was calculated using the linear-fit slope of the potential over the measurement period.

Similar recording was also performed for the response-time experiment. The open-circuit potential was initially recorded in a $5 \mathrm{~mL}$ stirred solution of $20 \mathrm{mM} \mathrm{KH}_{2} \mathrm{PO}_{4}, 137 \mathrm{mM} \mathrm{NaCl}$, and $5 \mathrm{mM} \mathrm{KCl}$. The solution was stirred with a magnetic stirrer hovering above the electrode. Over time, different amounts of $0.5 \mathrm{M} \mathrm{K}_{2} \mathrm{HPO}_{4}$ were added (by pipetting) to change the proton concentration by $0.6 \mathrm{pH}$ units (except for the first addition, which resulted in a change of $1.2 \mathrm{pH}$ units due to the unbuffered nature of the initial solution). Response time was deduced by linear fitting of the slope and calculating the intersecting time points between the stable potential plateau and the slope.

The oxygen sensitivity measurement was done in a $\mathrm{pH} 7$ buffer, which had been purged with $\mathrm{N}_{2}$ gas for $1 \mathrm{~h}$. Open-circuit measurement began with the buffer still purged with $\mathrm{N}_{2}$ gas. After $\sim 4 \mathrm{~h}$ of measurement, the $\mathrm{N}_{2}$ gas was stopped and the buffer solution purged with instrument air (compressed, filtered air, free of contaminates) instead. The measurement was left to record for another $\sim 4 \mathrm{~h}$.

\section{Results}

\subsection{Fabrication and Characterization}

Every heat-annealed RuOx was imaged by SEM to confirm the creation of nanorods. An example of the produced nanorods sample is given in Figure 1b. As a comparison, Figure 1a shows the freshly precipitated precursor on silicon. As can be seen, the heat treatment did not convert all amorphous precursor into nanorods. The conversion seemed to depend on a few different parameters, most notably the substrate material and cleanness, as well as the presence of organics during the heat 
treatment. On (electrochemically) cleaned Pt substrate and in the absence of organics during heat treatment, nanorods typically grew (rather sparingly) on the precursor, as shown in Figure 1b. Most of the nanorods were around $50 \mathrm{~nm}$ wide and 200-350 nm long, forming a pointy rod shape as its width tapers along the length.

$\mathrm{RuO}_{2}$ stoichiometry was confirmed using energy-dispersive X-ray spectroscopy (EDX). EDX measurement of annealed $\mathrm{RuOx}$ with a visible nanorods morphology sample (shown in Supplementary Information (SI) Figure S1) revealed a Ru to O ratio of approximately 1:2.

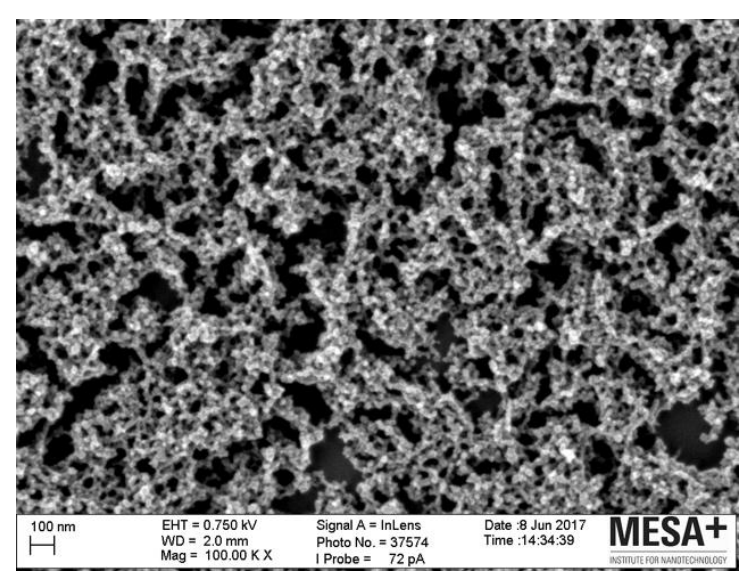

(a)

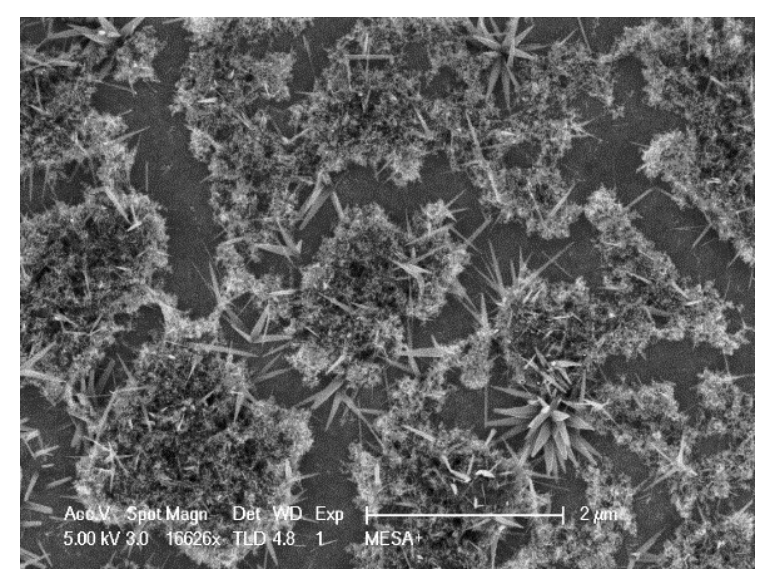

(b)

Figure 1. Scanning electron microscopy (SEM) images of the ruthenium oxide (RuOx) electrode: (a) Precipitated $\mathrm{Ru}(\mathrm{OH})_{3}$ precursor, isolated and spread onto a silicon surface; (b) heat-treated precursor (at $350{ }^{\circ} \mathrm{C}$, for $3 \mathrm{~h}$ ) on a platinum electrode surface formed $\mathrm{RuO}_{2}$ nanorods with a width of around $50 \mathrm{~nm}$ and length of 200-350 $\mathrm{nm}$.

\section{2. $p H$ Sensitivity and Selectivity}

The open-circuit potential of the $\mathrm{RuOx}$ electrode as a function of $\mathrm{pH}$ is shown in Figure 2. Figure $2 \mathrm{a}$ shows the typical potential response in air-saturated $\mathrm{pH}$ buffers from $\mathrm{pH} 4-10$. The mean of the three different measurements (using three different electrodes) is plotted, with the error bar showing one standard deviation among the data. The slope of linear fitting through the measurement points indicates the electrode $\mathrm{pH}$ sensitivity of $-58.1 \pm 1.2 \mathrm{mV} / \mathrm{pH}$, with extrapolated $\mathrm{E}^{0}$ of $736 \pm 18 \mathrm{mV}$.

The RuOx electrode was also tested for its selectivity against possibly interfering ions, namely lithium, sulfate, chloride, and calcium ions. The potential response towards the different ions is given in Figure $2 \mathrm{~b}$. The highest sensitivity, taken from the slope of linear fitting through the points, was found towards lithium ions. This response of $1.06 \mathrm{mV} / \mathrm{decade}\left[\mathrm{Li}^{+}\right]$is also plotted in Figure $2 \mathrm{a}$ as a comparison to the $\mathrm{pH}$ response.

The $\mathrm{RuOx}$ electrode was also tested for its $\mathrm{pH}$ response in a physiologically relevant milieu for future organs-on-chip applications. A solution comprising of $137 \mathrm{mM} \mathrm{NaCl}, 5 \mathrm{mM} \mathrm{KCl}$, and $2 \mathrm{mM}$ $\mathrm{KH}_{2} \mathrm{PO}_{4}$, which make up the inorganic constituent of human body fluids, was used. Different amounts of $0.5 \mathrm{M} \mathrm{KHPO}_{4}$ was added to the solution to vary the $\mathrm{pH}$ between 6 and 8 , while making sure the solution was relatively isotonic to human body fluids. An open-circuit potential measurement of an $\mathrm{RuOx}$ electrode is plotted in Figure 3 as a function of the solution's $\mathrm{pH}$. A sensitivity of $-58.23 \mathrm{mV} / \mathrm{pH}$ was estimated from linear fitting. 


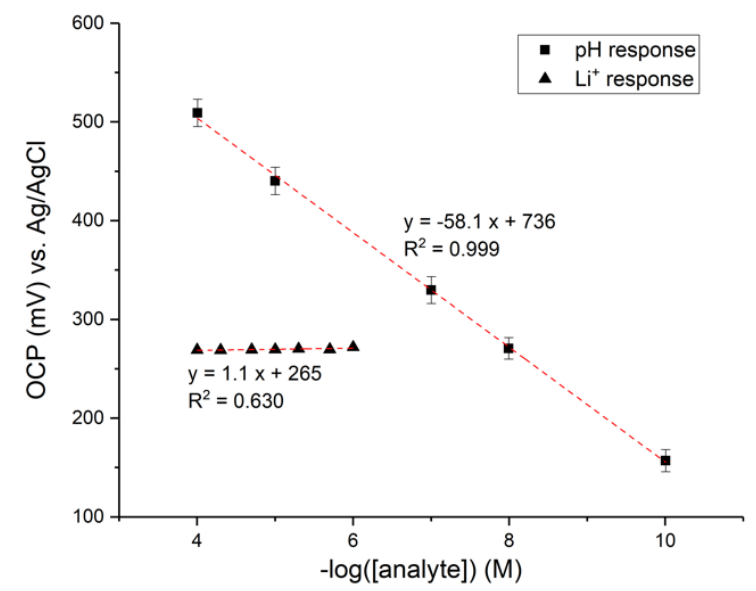

(a)

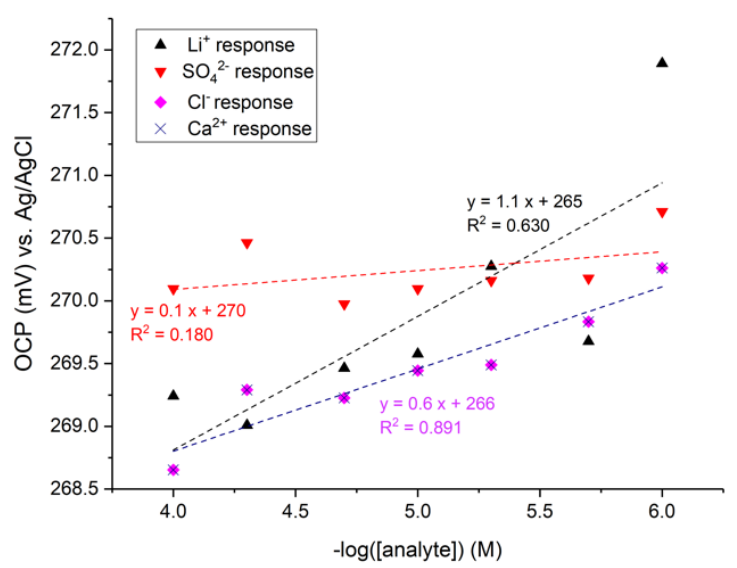

(b)

Figure 2. Experimental results of the RuOx electrode: (a) Open-circuit potential of the RuOx electrode in different $\mathrm{pH}$ buffer solutions. The error bar shows one standard deviation out of three different sets of measurement. Largest cross-sensitivity, towards lithium ions, is plotted as a comparison. Dashed lines are linear fitting through the points; (b) open-circuit potential of the RuOx electrode with the presence of different ions (lithium, sulfate, chloride, calcium ions) in $\mathrm{pH} 7.4$ buffer. Dashed lines are linear fitting through the points.

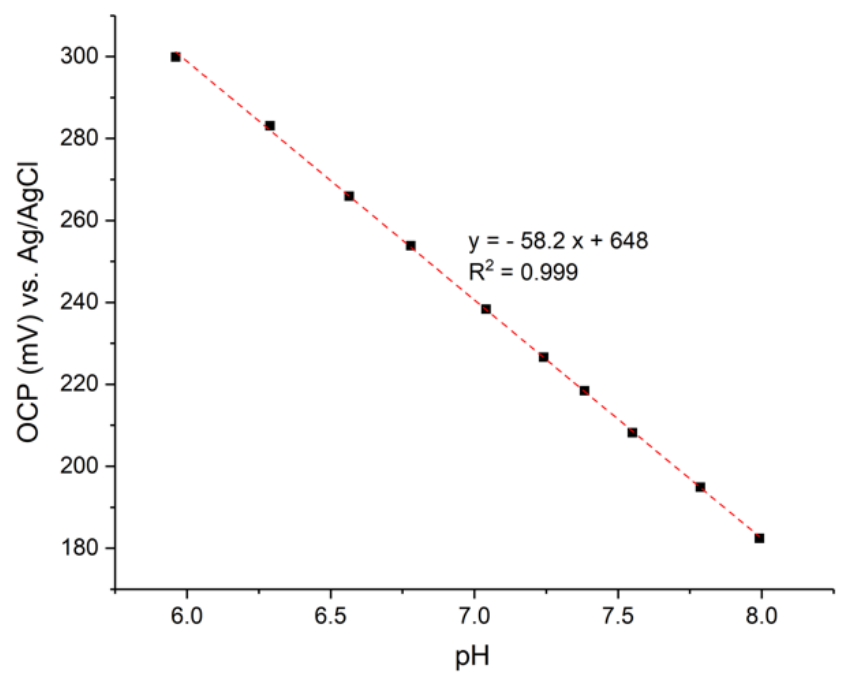

Figure 3. Open-circuit potential of (preconditioned) RuOx electrode in isotonic PBS buffer with a $\mathrm{pH}$ range of 6-8. Dashed line is linear fitting through the points.

\subsection{Drift and Aging}

Drift behavior of the RuOx electrode was also studied. Freshly prepared or dry-stored electrodes were observed to undergo large short-term drift, decaying into a linear long-time drift after 8-10 h of measurement in a buffer. Preconditioning of the electrode, simply by storing it in liquid, allowed it to immediately attain the lesser long-term drift, as shown below in Figure 4a. 


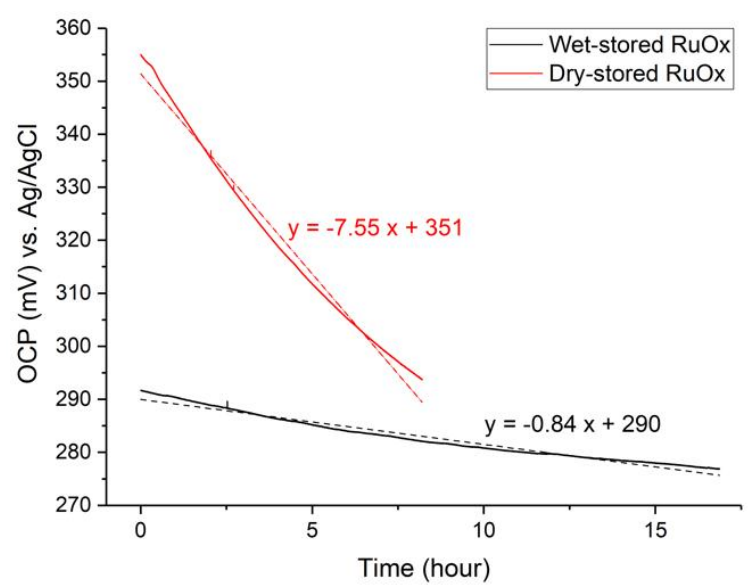

(a)

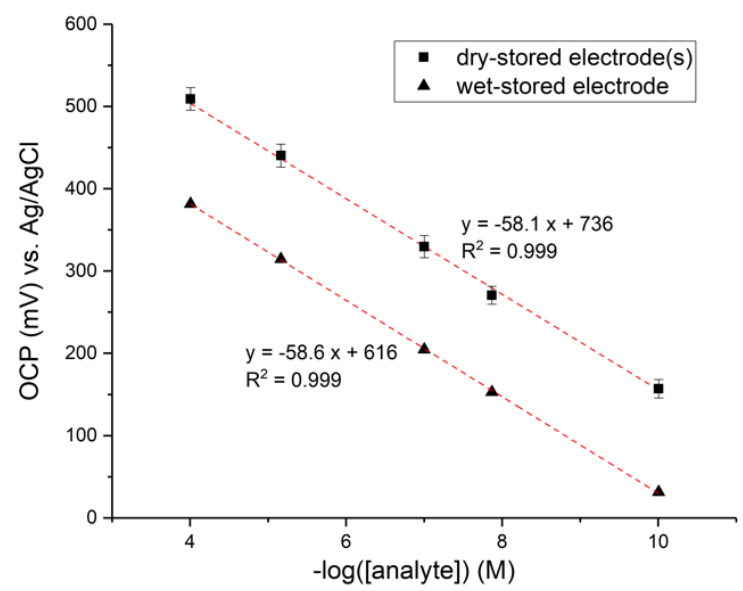

(b)

Figure 4. (a) Open-circuit potential of RuOx recorded over time in $\mathrm{pH} 7$ buffer, fitted linearly (dotted lines). RuOx electrode showed high drift when stored in air (dry-stored) and significantly lower drift when stored in liquid (wet-stored); (b) comparison of open-circuit potential of wet-stored vs. dry-stored $\mathrm{RuOx}$ in different $\mathrm{pH}$ buffers, fitted linearly.

The open-circuit potential of $\mathrm{RuOx}$ electrode was measured over a long period of time in air-saturated pH 7 buffer, firstly after it had been stored in air (dry-stored RuOx graph). The measurement was then repeated with the same electrode after it had been stored in $\mathrm{pH} 7 \mathrm{buffer}$ overnight (wet-stored RuOx graph). Dry-stored RuOx electrode showed a high drift of around $-7.5 \mathrm{mV} / \mathrm{h}$. Wet-stored RuOx electrode showed a significantly lower drift of $-0.8 \mathrm{mV} / \mathrm{h}$. The behavior was highly reversible, with the wet-stored electrodes again undergoing the large drift after drying (dry-blowing with $\mathrm{N}_{2}$ ). Furthermore, the wet-stored RuOx electrode performed comparably well to the freshly prepared/air-stored RuOx electrode in terms of $\mathrm{pH}$ sensitivity, as shown in Figure $4 \mathrm{~b}$.

At the time of writing, a number of RuOx electrodes had been used for as much as 10 months since their fabrication. The electrodes were stored in DI water for most of the time. So far, no detrimental effects on $\mathrm{pH}$ sensitivity, drift, or response time have been noticed from using, rinsing, and $\mathrm{pH}$-cycling (between $\mathrm{pH} 2-10$ ) the electrodes. Exposure of the electrodes to biological cell culture medium or bovine serum albumin also did not affect the electrode's $\mathrm{pH}$-sensing performance. $\mathrm{pH}$ response calibration after extensive exposure to culture medium and bovine serum albumin showed reproducible $-58 \mathrm{mV} / \mathrm{pH}$ sensitivity.

\subsection{Response Time}

Filtered recording of RuOx open-circuit potential is shown in Figure 5, during which the solution $\mathrm{pH}$ was changed (the first change by $1.2 \mathrm{pH}$ unit, the following by $0.6 \mathrm{pH}$ unit). Due to the introduction of a magnetic stirrer in the Faraday cage during measurement, a noisy signal was acquired. For ease of analysis, a low-pass (cut off at $\sim 40 \mathrm{~Hz}$ ) and band-stop (cut off around the frequency of the magnetic stirrer, between 3 and $3.5 \mathrm{~Hz}$ ) filters were applied, resulting in the graph shown in Figure 5. The raw signal can be seen in SI Figure S4. Analysis of the slopes resulted in a calculated response time between 2 and $3 \mathrm{~s}$. 


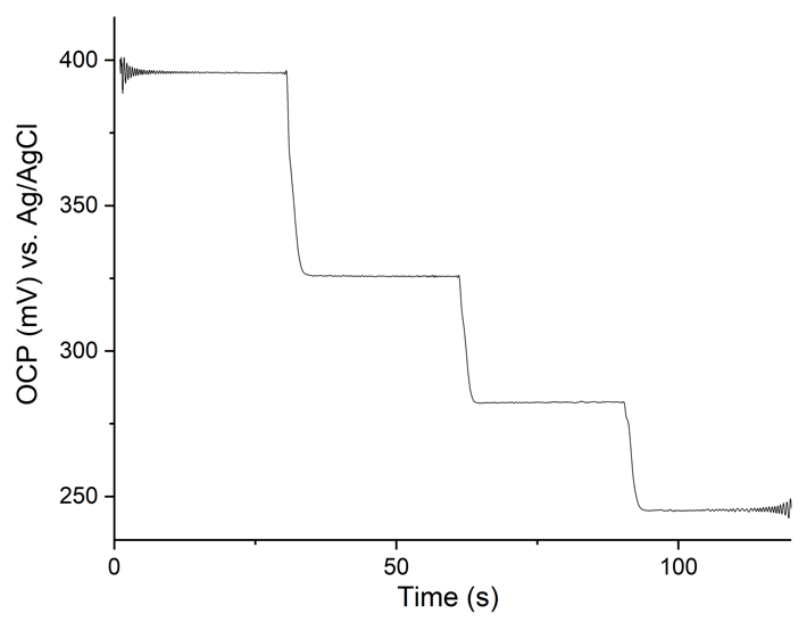

Figure 5. Open-circuit potential recording of the RuOx electrode in changing $\mathrm{pH}$, low-pass filtered with cut-off frequency of $\sim 40 \mathrm{~Hz}$.

\subsection{Oxygen Sensitivity}

Open-circuit potential recording of the $\mathrm{RuOx}$ electrode in $\mathrm{pH}$ buffer with changing oxygen levels is shown in Figure 6. The negatively sloping potential recording in the first $4 \mathrm{~h}$ (linearly fitted with the blue dashed line) occurred in deaerated buffer solution and was of the same order of magnitude as the earlier observed wet-stored drift. A positive slope was observed in the following $4 \mathrm{~h}$ as reoxygenation took place in the buffer. Over the entire $4 \mathrm{~h}$, the open-circuit potential drifted $3 \mathrm{mV}$ as the buffer went from being deoxygenated to oxygenated. Large spikes in the recording were motion artefacts.

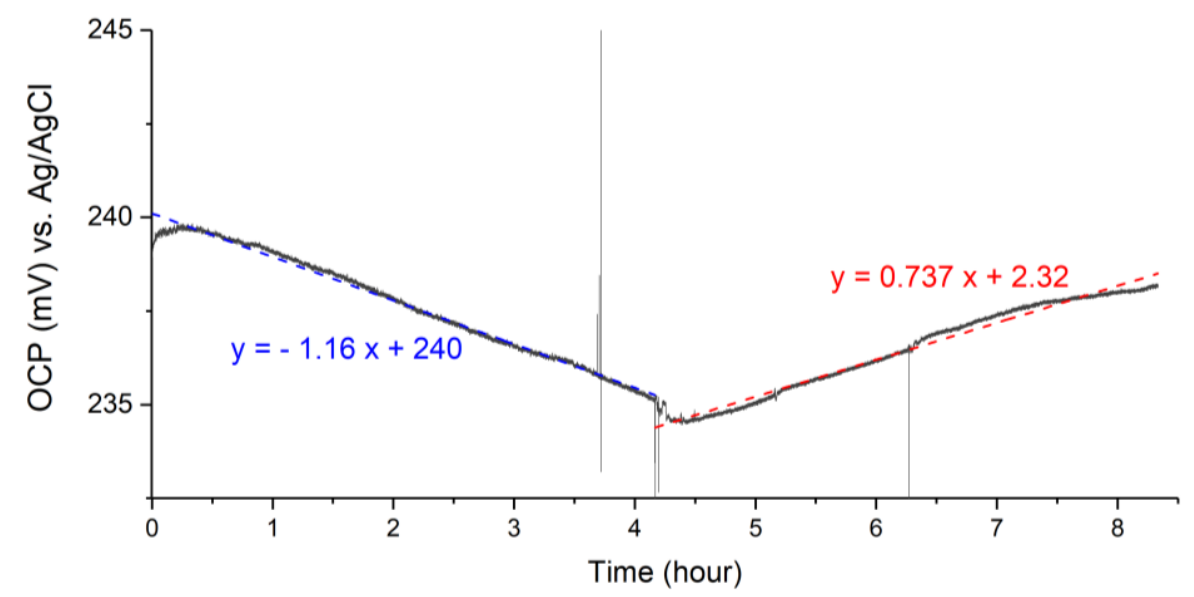

Figure 6. Open-circuit potential recording of wet-stored RuOx electrode, for the first $4 \mathrm{~h}$ in deaerated $\mathrm{pH} 7$ buffer, followed by $4 \mathrm{~h}$ of reoxygenated $\mathrm{pH} 7$ buffer. Fitted linearly by the dashed lines.

\section{Discussion}

\section{1. $p H$ Response and Selectivity}

Near-Nernstian $\mathrm{pH}$ sensitivity was demonstrated by a number of different RuOx nanorods electrodes (Figure 2a). Based on the reaction given in Equation 1, the expected electrode potential at $25^{\circ} \mathrm{C}$ in different $\mathrm{pH}$ can be expressed as $[8,10]$ :

$$
\mathrm{E}=-0.059 \mathrm{~V} \cdot \mathrm{pH}+0.740 \mathrm{~V}(\mathrm{vs} . \mathrm{Ag} / \mathrm{AgCl})
$$


The fitted experimental expression shown in Figure 2a (sensitivity of $-58.05 \mathrm{mV} / \mathrm{pH}$ and extrapolated $\mathrm{E}^{0}$ of $0.73621 \mathrm{~V}$ ) comes in very good agreement with the theoretical values, affirming the proposed $\mathrm{pH}$-sensing theory.

A typical $\mathrm{RuOx}$ nanorods electrode surface (as shown in Figure $1 \mathrm{~b}$ ) exposes the annealed $\mathrm{RuO}_{2}$ nanorods, the amorphous $\mathrm{Ru}(\mathrm{OH})_{3}$ precursor, and the Pt surface. Presumably, the Pt surface would have an oxide layer, created both during the electrochemical cleaning process as well as during the heat treatment. $\mathrm{PtO}_{2}$ has also been reported as being a $\mathrm{pH}$-sensitive metal oxide [4,17]. However, it is known that the potential $\mathrm{pH}$ response of $\mathrm{PtOx}$ is often lower than the Nernst-predicted $-59 \mathrm{mV} / \mathrm{pH}[4,17]$. It is also supported by our own observations of $\mathrm{PtOx} \mathrm{pH}$ sensitivity of $-34.46 \mathrm{mV} / \mathrm{pH}$ (SI, Figure S3). Therefore, it can be assumed that the observed near-Nernstian $\mathrm{pH}$ response is attributed to the RuOx modification.

As mentioned, the RuOx nanorods conversion seems to depend on several parameters. Unfortunately, the exact influence of the different parameters is not yet fully understood, which often challenges the reproducibility of the nanorods fabrication. While the typical resulting surface is shown in Figure 1b, different morphology of the nanorods has been observed across different fabrication batches. Nonetheless, the different morphology of RuOx nanorods does not seem to influence the potentiometric signal extensively. RuOx nanorods electrodes with different distributions and nanorods sizes performed comparably well in terms of their $\mathrm{pH}$ response.

The RuOx $\mathrm{pH}$ response was experimentally characterized between $\mathrm{pH} 4-10$. Linear potential-pH response has been reported over a larger $\mathrm{pH}$ range for $\mathrm{RuO}_{2}[4,8,17]$. However, the potential-pH graph (Pourbaix diagram) of ruthenium suggests that $\mathrm{RuO}_{2}$ becomes unstable in $\mathrm{pH}$ larger than $10[9,18,19]$. Keeping the organs-on-chip applications in mind, a closer investigation was done in the narrower, but more physiologically relevant, $\mathrm{pH}$ range instead.

Metal oxides are known to be readily complexed by different (an-)ions [8,18]. Operating in intricate (biological) milieu will inevitably expose the RuOx electrode to different, and possibly complexing or interfering, ions. Therefore, the effect of these ions on the electrode's performance was studied. Relatively unchanging open-circuit potential in changing concentrations of different ions suggests the electrode was not extensively complexed by the ions in the solution, and is therefore sufficiently stable for the foreseen application. Residual sensitivity to the tested ions was so negligible that noise dominated the signal, resulting in poor signal-to-concentration linearity (shown by the low $\mathrm{R}^{2}$ values of linear fit).

The electrode response was also not interfered with when tested in $\mathrm{pH}$ buffers with (physiologically) isotonic osmolarity. The comparable near-Nernstian response in isotonic $\mathrm{pH}$ buffers suggests that good reproducibility can be expected of the RuOx nanorods electrodes when employed in biological milieu.

\subsection{Drift and Aging}

As mentioned, the RuOx electrode drifts differently when the electrode has been stored in air than when it has been stored in liquid. A large short-term drift was observed from freshly prepared or dry-stored RuOx electrodes, which decayed into a long-term drift of lower magnitude after a 8-10 h immersion in liquid. It was also demonstrated that electrodes stored/aged in liquid immediately showed a lower magnitude drift (Figure 4a). It could also be seen from the measurements (Figure 2a, Figure 3, and Figure 4) that this aging process resulted in a change of $\mathrm{E}^{0}$ value of around -60 to $-100 \mathrm{mV}$. This drift decay and the shift in $\mathrm{E}^{0}$ value after the aging metal oxide electrode in liquid was reported across different metal oxide electrodes $[6-8,10,20,21]$. Literature has attributed this behavior either to the effect of hydration on the metal oxides' surface $[8,17]$, to redox processes involving atmospheric oxygen [7], or to the chemical modification of the hydroxide groups on the oxide surface [22]. Looking at the marginal response of the RuOx to changing oxygenation (Figure 6), it is unlikely that atmospheric oxygen alone caused the observed large drift. The work of McMurray et al. [8] also showed similar drift/aging behavior, albeit their electrode being described as 
completely indifferent to oxygen concentration. Given the highly reversible drift behavior, it is also unlikely that chemical modification caused the drift. The reversibility, however, is in line with the hydration phenomenon. Slow hydration could take place on the RuOx surface, introducing a change in surface energy, thus giving rise to the potential drift. It is also in line with the proposed sensing theory, where the equilibrium involves two hydrated forms of RuOx. Based on the observed drift behavior and in view of the literature, it can be reasonably concluded that the slow surface hydration is what gives rise to the observed drift.

The long-term drift of wet-stored RuOx electrode was observed to be $-0.8 \mathrm{mV} / \mathrm{h}$ (Figure $4 \mathrm{a}$ ), which corresponds to a $\Delta \mathrm{pH}$ of 0.013 per hour. Such a potential drift can be sufficient for measurements over several hours in organs-on-chip applications. More accurate and longer measurements can also be achieved, should on-chip recalibration strategy be feasible to implement.

\subsection{Response Time and Oxygen Sensitivity}

The reaction time experiment suggested that the system reacted to the introduced $\mathrm{pH}$ change within 2 to $3 \mathrm{~s}$. However, it was noticed that the resulting signal (particularly the slope) was highly dependent on how the solution was pipetted into the electrochemical cell. Keeping the setup and the protocol in mind, it can be assumed that the rate at which the $\mathrm{pH}$ change was practically introduced was the limiting rate. Therefore, it can be concluded that the sensor's true response time is less than $2 \mathrm{~s}$. Such a response time is more than sufficient for the foreseen organs-on-chip applications, where $\mathrm{pH}$ change does not tend to occur so rapidly.

The oxygen sensitivity experiment showed a potential drift as low as $3 \mathrm{mV}$ going from deoxygenated to oxygenated buffer. The potential shift corresponds to a $\Delta \mathrm{pH}$ of 0.05 . This proved to be significantly lower than other reported metal oxide sensors. $\mathrm{IrO}_{2}$ has also been reported to drift as much as $80 \mathrm{mV}$, going from deoxygenated to oxygenated buffer [6,7]. The PdO electrode, which showed a $\mathrm{pH}$ sensitivity of $-54 \mathrm{mV} / \mathrm{pH}$ in oxygenated buffer, is rendered non-functional in deoxygenated buffer [23]. Given the necessity to operate in a wide range of oxygen levels, the RuOx proves to be a strong contender for the $\mathrm{pH}$ sensor in organs-on-chip applications. The apparent $\mathrm{pH}$ drift of a $0.050 \mathrm{pH}$ unit going from deoxygenation to oxygenation is sufficiently low to allow for the accurate online monitoring of $\mathrm{pH}$ even in an oxygen-fluctuating environment, e.g., during a hypoxia study.

\section{Conclusions and Outlook}

The RuOx nanorods electrode was successfully fabricated through heat annealing of the $\mathrm{Ru}(\mathrm{OH})_{3}$ precursor. The electrode showed a near-Nernstian response to a $\mathrm{pH}$ of $-58 \mathrm{mV} / \mathrm{pH}$, which can be elucidated by a reversible redox reaction involving protons. The electrode proved to be a suitable $\mathrm{pH}$ sensor for future organs-on-chip applications, namely in terms of selectivity, drift $(-0.8 \mathrm{mV} / \mathrm{h}$ or $0.013 \mathrm{pH}$ unit/hour), response time (less than $2 \mathrm{~s}$ ), and oxygen sensitivity ( $\Delta \mathrm{pH}$ of 0.05 going from oxygenated to deoxygenated). Future work includes application of the $\mathrm{RuOx}$ nanorods $\mathrm{pH}$ sensor in a hypoxic cardiomyocytes study, as well as investigating the same RuOx nanorods sensor for its amperometric nitric oxide sensing abilities. For a hypoxia study application, current chips can readily be used together with a Transwell insert in the chip holder. Use of a solid-state quasi $\mathrm{Ag} / \mathrm{AgCl}$ reference electrode and miniaturization of the RuOx electrode are planned for future integration within a micro-chamber/channel.

Supplementary Materials: The following are available online at http:/ /www.mdpi.com/1424-8220/18/9/2901/ s1, Figure S1: EDX result of annealed RuOx, emitted photo electrons characteristic to oxygen and ruthenium were detected; Figure S2: Open-circuit potential signal of RuOx in different $\mathrm{pH}$ buffers is plotted over time. Last OCP point is taken as potential response of the solution's $\mathrm{pH}$ for plotting; Figure S3: Open-circuit potential of bare Pt electrode as a function of $\mathrm{pH}$, dashed line is linear fitting through the points; Figure S4: The noisy raw signal (blue) from the response time experiment overlaid with the filtered signal (low pass, cut-off frequency of $\sim 40 \mathrm{~Hz}$ and band-stop, between 3-3.5 Hz) (green). Inset shows a closer view of the slope area. 
Author Contributions: Conceptualization, W.O.; Formal analysis, E.T.; Funding acquisition, A.v.d.B.; Investigation, E.T.; Methodology, E.T. and W.O.; Supervision, W.O. and A.v.d.B.; Writing—original draft, E.T.; Writing-review \& editing, W.O.

Funding: This research was funded by European Research Council (ERC) under the European Union's Horizon 2020 research and innovation programme (grant agreement No. 669768).

Acknowledgments: Great thanks are extended to Andries van der Meer and Andre ten Elshof for their valuable scientific input. Many thanks are also extended to Hugo Albers and Rolf Slaats for their input and work especially towards sensor's applicability in organs-on-chip. Authors are also grateful of Mark Smithers for his help in SEM imaging and EDX measurement, of Johan Bomer for his technical input and assistance, of Hans de Boer for his work in the fabrication of chip-holder, and of Jan Eijkel for his input in the manuscript preparation.

Conflicts of Interest: The authors declare no conflict of interest.

\section{References}

1. Bhatia, S.N.; Ingber, D.E. Microfluidic organs-on-chips. Nat. Biotechnol. 2014, 32, 760-772. [CrossRef] [PubMed]

2. Huh, D.; Hamilton, G.A.; Ingber, D.E. From 3D cell culture to organs-on-chips. Trends Cell Biol. 2011, 21, 745-754. [CrossRef] [PubMed]

3. Van der Meer, A.D.; van den Berg, A. Organs-on-chips: Breaking the in vitro impasse. Integr. Biol. 2012, 4, 461-470. [CrossRef] [PubMed]

4. Fog, A.; Buck, R.P. Electronic semiconducting oxides as pH sensors. Sens. Actuators 1984, 5, $137-146$. [CrossRef]

5. Głab, S.; Hulanicki, A.; Edwall, G.; Ingman, F. Metal-Metal Oxide and Metal Oxide Electrodes as pH Sensors. Crit. Rev. Anal. Chem. 1989, 21, 29-47. [CrossRef] [PubMed]

6. Katsube, T.; Lauks, I.; Zemel, J.N. pH-sensitive sputtered iridium oxide films. Sens. Actuators 1981, 2, 399-410. [CrossRef]

7. Olthuis, W.; Robben, M.A.M.; Bergveld, P.; Bos, M.; van der Linden, W.E. pH sensor properties of electrochemically grown iridium oxide. Sens. Actuators B Chem. 1990, 2, 247-256. [CrossRef]

8. McMurray, H.N.; Douglas, P.; Abbot, D. Novel thick-film pH sensors based on ruthenium dioxide-glass composites. Sens. Actuators B Chem. 1995, 28, 9-15. [CrossRef]

9. Pourbaix, M. Atlas of Electrochemical Equilibria in Aqueous Solutions; National Association of Corrosion Engineers: Houston, TX, USA, 1974.

10. Kurzweil, P. Metal Oxides and Ion-Exchanging Surfaces as pH Sensors in Liquids: State-of-the-Art and Outlook. Sensors 2009, 9, 4955-4985. [CrossRef] [PubMed]

11. Lonsdale, W.; Wajrak, M.; Alameh, K. Manufacture and application of $\mathrm{RuO}_{2}$ solid-state metal-oxide $\mathrm{pH}$ sensor to common beverages. Talanta 2018, 180, 277-281. [CrossRef] [PubMed]

12. $\mathrm{Xu}, \mathrm{B}$; Zhang, $\mathrm{W}$. De Modification of vertically aligned carbon nanotubes with $\mathrm{RuO}_{2}$ for a solid-state $\mathrm{pH}$ sensor. Electrochim. Acta 2010, 55, 2859-2864. [CrossRef]

13. Lonsdale, W.; Maurya, D.K.; Wajrak, M.; Tay, C.Y.; Marshall, B.J.; Alameh, K. Rapid measurement of urease activity using a potentiometric $\mathrm{RuO}_{2} \mathrm{pH}$ sensor for detection of Helicobacter pylori. Sens. Actuators $B$ Chem. 2017, 242, 1305-1308. [CrossRef]

14. Manjakkal, L.; Cvejin, K.; Kulawik, J.; Zaraska, K.; Szwagierczak, D.; Socha, R.P. Fabrication of thick film sensitive $\mathrm{RuO}_{2}-\mathrm{TiO}_{2}$ and $\mathrm{Ag} / \mathrm{AgCl} / \mathrm{KCl}$ reference electrodes and their application for $\mathrm{pH}$ measurements. Sens. Actuators B Chem. 2014, 204, 57-67. [CrossRef]

15. Zhuiykov, S. Morphology of Pt-doped nanofabricated $\mathrm{RuO}_{2}$ sensing electrodes and their properties in water quality monitoring sensors. Sens. Actuators B Chem. 2009, 136, 248-256. [CrossRef]

16. Chen, Z.G.; Pei, F.; Pei, Y.T.; De Hosson, J.T.M. A Versatile Route for the Synthesis of Single Crystalline Oxide Nanorods: Growth Behavior and Field Emission Characteristics. Cryst. Growth Des. 2010, 10, 2585-2590. [CrossRef]

17. Kreider, K.G.; Tarlov, M.J.; Cline, J.P. Sputtered thin-film pH electrodes of platinum, palladium, ruthenium, and iridium oxides. Sens. Actuators B. Chem. 1995, 28, 167-172. [CrossRef]

18. Dietz, T.; Kreider, K.G. Review of Materials for pH Sensing for Nuclear Waste Containment; National Bureau of Standards Interagency Report: Gaithersburg, MD, USA, 1985. 
19. Rard, J.A. Chemistry and Thermodynamics of Ruthenium and Some of Its Inorganic Compounds and Aqueous Species. Chem. Rev. 1986, 86, 731. [CrossRef]

20. Tarlov, M.J.; Semancik, S.; Kreider, K.G. Mechanistic and response studies of iridium oxide pH sensors. Sens. Actuators B Chem. 1990, 1, 293-297. [CrossRef]

21. Kinoshita, K. Electrochemical Measurements on Pt, Ir, and Ti Oxides as pH Probes. J. Electrochem. Soc. 1984, 131, 1089. [CrossRef]

22. Mihell, J.A.; Atkinson, J.K. Planar thick-film $\mathrm{pH}$ electrodes based on ruthenium dioxide hydrate. Sens. Actuators B Chem. 1998, 48, 505-511. [CrossRef]

23. Karagounis, V.A.; Liu, C.C.; Neuman, M.R.; Romankiw, L.T.; Leary, P.A.; Cuomo, J.J. A Pd-PdO Film Potentiometric pH Sensor. IEEE Trans. Biomed. Eng. 1986, BME-33, 113-116. [CrossRef]

(C) 2018 by the authors. Licensee MDPI, Basel, Switzerland. This article is an open access article distributed under the terms and conditions of the Creative Commons Attribution (CC BY) license (http:// creativecommons.org/licenses/by/4.0/). 